\title{
Adaptation of the Application of Good Clinical Practice Depending on the Features of Specific Research Projects
}

\author{
Pierre-Henri Bertoye, ${ }^{1}$ Soizic Courcier-Duplantier ${ }^{2}$, Nicolas Best ${ }^{3}$ \\ and the participants in Round Table $N^{\circ} 2$, Giens XXI ${ }^{\star}$ \\ 1 Afssaps, Saint Denis, France \\ 2 Bristol Myers Squibb, Rueil Malmaison, France \\ 3 DRRC, Hôpital Saint Louis, Paris, France
}

\section{Keywords:}

clinical trails;

GCP;

adaptation;

implementation;

risks;

challenges;

monitoring;

medicinal product

circuit;

pharmacovigilance

\begin{abstract}
The conduct of clinical trials falls within a strict regulatory framework. The objective of the round table was to develop reasonable recommendations for the implementation of GCP according to the type of research and taking in account the risks and challenges related to this research. Two types of risks have been identified: those related to the characteristics of the research and those related to the impact of the study results. The group designed an evaluation table of these risks. The round table focused its investigations on 3 main themes: monitoring, the investigational medicinal product and undesirable effects. Three methods of monitoring adaptation were analysed in terms of advantages and disadvantages: the gradual approach, the central monitoring, monitoring on the basis of sampling. Examination of the investigational medicinal product focused on the medicinal product circuit. The group recommends using the following 'basic' decision-making tree, which takes three elements into account: 1) is it an investigational medicinal product?,2) do the trial objectives and design require packaging specific to the research?, 3) is the risk of use higher than that in standard practice? Finally, adaptation of the implementation of GCP in terms of pharmacovigilance appeared very limited and could possibly be considered for the medicinal product, the subject of the research, which already holds a marketing authorisation, and for which the safety profile is well known; in this case, only simplified collection of non-serious adverse events may be envisaged, which may be implemented by designing and using a standard collection listing.

The adaptation of the implementation of GCP is possible. This firstly takes into account the characteristics of the research: which objectives/which risks/which challenges. The options in terms of adaptation must be pre-defined, documented and justified; if necessary, they will also be re-assessed in the course of analysis.
\end{abstract}

A clinical trial is designed to obtain results which provide a credible answer to the question asked about a medicinal product or treatment, without subjecting the people who undergo it to needless risk. ${ }^{[1]}$ The quality of the design, execution and monitoring of a clinical trial influences both the safety and protection of people undergoing in the trial, as well as the acceptability and reliability of the results obtained about a medicinal product or treatment strategy, whether these results form the subject of a publication and/or a marketing authorisation (MA) dossier.

Respect of quality is organised and controlled by the systematic use of procedures through the application of Good Clinical Practice $(\mathrm{GCP}){ }^{[2]}$

${ }^{\star}$ For the list of participants, please see the end of the article.
Clinical trials are conducted within a strict regulatory framework which was recently modified at the European level by Directive 2001/20/EC dated 4 April 2001 [3] "on the approximation of the laws, regulations and administrative provisions of the Member States relating to the implementation of Good Clinical Practice in the conduct of clinical trials on medicinal products for human use".

This directive has been transposed in France into the Guidance Law on Public Health of 9 August 2005 (Book 1, Chapter II of the Code of Public Health), ${ }^{[4]}$ the application decree is now published. ${ }^{[5]}$

A directive for the application of Directive 2002/20/EC, Directive 2005/28/EC dated 8 April $2005,{ }^{[6]}$ is designed to apply 
GCP and recalls in its considerations and in its first chapter a draft guide relating to specific methods for the application of GCP for academic studies. This draft guide, entitled "specific modalities for academic research" is currently being drafted at the European level and is expected to be circulated for comments during 2006.

In this setting, the aim of Round Table no. 2 of the Giens XXI Clinical Pharmacology National meeting was to produce reasonable recommendations for the application of GCP in the context of certain types of research, taking account of the stakes of the research.

The aim of these recommendations were:

- firstly to extend discussion or practices already used in some research structures,

- secondly to establish a consensus viewpoint between the different partners (institutional, clinicians, patients, companies) which may be presented and discussed on a community level to inform the debate on the European "specific modalities for academic research" guide currently being drafted (France and Great Britain being the reporter countries).

The scope of the discussion was firstly determined precisely by defining the type of research in which an adaptation of the application of GCP could be considered.

It was decided on a consensus basis that the work of the round table:

- would only involve research on medicinal products which, by obligation, require marketing authorisation (MA),

- would exclude all post-MA "regulatory" studies, i.e. those performed prospectively in the context of a conditional MA or as research for a new indication; and

- would be restricted to interventional clinical trials and not consider non-interventional trials, for which the French regulations set the precise boundaries.

By means of example, the following were included in the scope of the round table:

- post-MA clinical safety trials, as described in the ICHE2E Guide $^{[7]}$ designed to study the potential risks identified - adverse effects or undesirable events which require more precise evaluation and/or characterisation,

- clinical trials designed to specify an indication (subpopulation, contra indication, etc.) leading to publications which may influence medical or therapeutic good practice recommendations (for example: aspirin in patients with renal insufficiency to prevent thrombo-embolic events), and

- comparative clinical trials of therapeutic or diagnostic strategies.
It subsequently appeared essential to identify and evaluate the risks and demands of the research before considering any adaptation of application of GCP: ${ }^{[8]}$ identifying the risk associated with the substance for the trial patients, the risk associated with the investigations and the risk associated with the quality of the research results for the target population. In Great Britain, the Medical Research Council's work on this type of risk assessment has led to complex monitoring definition algorithms. ${ }^{[9]}$

This assessment must be conducted as early as possible, and be described, documented and detailed in order to construct a genuine monitoring plan, in terms of these risks and demands, for the research. ${ }^{[1]}$

Two types of risk were identified:

- firstly, risks associated with the features of the research:

○ trial patients (specific at risk populations?...),

- medicinal product (specific toxicity?...),

- dangers associated with the protocol (invasive investigations, changes in the patients' usual care plan...),

$\circ$ design and trial plan of the trial; and

- structure responsible for the research (clinical research experience?...),

- and subsequently, the demands associated with the impact of the research results:

o demands on therapeutic practices (will the results have an impact and what risk exists if the results of the trial are erroneous?),

- financial demands, and

- need for results and difficulty of duplicating the trial if necessary.

In order to best assess these risks and demands, the group constructed an assessment grid (Table I) to review each of the criteria listed above and to assess them in the context of the research using a scale scored from 1 (low risk) to 4 (high risk).

This scale must be used as a continuum within with each criterion must be weighted. It is proposed that the grid be tested prospectively on academic and/or industrial research in order to assess its application, and to refine or add to it.

Once the scope had been defined and the risks and stakes assessed, the round table worked around 3 major topics:

- monitoring,

- the investigational medicinal product, and

- adverse effects.

\section{Adaptation of monitoring}

The discussion on adapting monitoring was based on a number of questions. 
Table I. Grading of risk from least risk (1) to greatest risk (4).

\begin{tabular}{|c|c|c|c|c|}
\hline Level of Risk & 1 & 2 & 3 & 4 \\
\hline Population (S) & MA Indications & & $\begin{array}{l}\text { Extreme age, pregnant } \\
\text { women }\end{array}$ & Significant failure of a system \\
\hline Medicinal product (S) & $\begin{array}{l}\text { Review of reassuring } \\
\text { and stabilised } \\
\text { knowledge }\end{array}$ & $\begin{array}{l}\text { Review of reassuring and } \\
\text { not entirely stabilised } \\
\text { knowledge }\end{array}$ & & $\begin{array}{l}\text { Recent MA ( }<2 \text { years) } \\
\text { Review of not reassuring or not } \\
\text { stabilised knowledge }\end{array}$ \\
\hline $\begin{array}{l}\text { Duration of treatment/ } \\
\text { dosage }(S)\end{array}$ & & & & $\begin{array}{l}\text { Unusual use: dose, duration, asso- } \\
\text { ciation }\end{array}$ \\
\hline $\begin{array}{l}\text { Other procedures } \\
\text { in the protocol }\end{array}$ & $\begin{array}{l}\text { Not particularly par } \\
\text { invasive (blood } \\
\text { sample) }(\mathrm{T})\end{array}$ & $\begin{array}{l}\text { Potentially dangerous } \\
\text { withdrawal of a treatment } \\
\text { (S) }\end{array}$ & $\begin{array}{l}\text { Change in the usual } \\
\text { care plan of patients }\end{array}$ & $\begin{array}{l}\text { Invasive procedure involving risk to } \\
\text { life, complex /multiple procedures } \\
(\mathrm{S} / \mathrm{T})\end{array}$ \\
\hline Major end point $(\mathrm{T})$ & Robust & & Composite criteria & Risk of major error \\
\hline $\begin{array}{l}\text { Consequences of } \\
\text { results: target } \\
\text { population }(T)\end{array}$ & & & Severity of the pathology & Trial which cannot be repeated \\
\hline $\begin{array}{l}\text { Financial impact } \\
\text { of the results }(T)\end{array}$ & & & & Major cost to the community \\
\hline
\end{tabular}

\subsection{What are the regulatory restrictions and what can be} adapted?

The GCP text from the ICH consensus reminds us firstly, in paragraph 5.18.3, ${ }^{[2]}$ that all trials must be monitored:

"The sponsor should ensure that the trials are adequately monitored. The sponsor should determine the appropriate extent and nature of monitoring. The determination of extent and nature of monitoring should be based on considerations such as the objective, purpose, design, complexity, blinding, size, and endpoints of the trial. In general there is a need for on-site monitoring, before, during and after the trial; however, in exceptional circumstances the sponsor may determine that central monitoring in conjunction with procedures such as investigators' training and meetings, and extensive written guidance can assure appropriate conduct of the trial in accordance with Good Clinical Practices. Statistically controlled sampling may be an acceptable method for selecting the data to be verified."

Therefore, it is explicitly stated in this text that the determination of the extent and modalities of the monitoring used must take account of the objective, complexity and type of the research. Whilst in the majority of cases on-site control should be preferred in some cases and under certain conditions the GCP text makes it possible to use centralised monitoring. The sponsor can also consider monitoring by sampling.

The sponsor will therefore need to in advance realistically evaluate the most efficient monitoring to be used, which may be a combination of the modalities described below.

\subsection{On what criteria should the decision to adapt monitoring be based?}

\subsubsection{Method 1: The Gradual Approach}

This approach applied by the Delegation of Clinical Research (DRC) of the Paris Public Assistance and Hospitals (AP-HP) is an example of adaptation already used taking account of the level of risk associated with the research and with the substance, and designed to guarantee the safety aspects of the clinical research, while at the same time taking account of available resources.

All of the projects promoted by the DRC are subject to an analysis based on the benefit/risk ratio for the participants.

4 classes of risk are recognised:

- risk A: low or negligible risk can be predicted (not applicable to trials on medicinal products), 
- risk B: risk which can be predicted similar to that of usual care,

- risk C: high predictable risk, and

- risk D: very high risk which can be predicted.

The research projects are classified by level of risk (Table II) and a gradual level of monitoring is applied depending on this level (Table III).

A prospective evaluation of this approach will be conducted in the OPTIMON trial: OPTImisation of MONitoring of institutional clinical research trials, co-ordinated by Madame Geneviève Chêne (Bordeaux Clinical Research Unit \& INSERM U593).

This is a randomised, multi-centre, non-blinded comparative trial designed to compare two monitoring strategies: classical monitoring and monitoring using a gradual approach inspired by the approach described above. The randomisation unit is the clinical centre within the same clinical research project.

Table I adds, to the risk criteria associated with the investigational substances and research investigations, considerations relative to the trial population, the complexity of the trial design and the impact of the quality of results. Therefore, it has been agreed that the criteria used for this gradual approach, which were formalised by the DRC AP-HP some years ago in order to reorganise the management of trials promoted by it, will be supplemented by other elements listed in Table I.

\subsubsection{Method 2: Centralised Monitoring}

Centralised monitoring is defined by the systematic organisation of feedback to the central monitor of pre-defined data essential to the trial. In the group's opinion, use of centralised monitoring cannot be considered without a minimum of on-site monitoring. ${ }^{[2]}$

The advantages of centralised monitoring are:

- savings of costs associated with on-site visits,

- greater flexibility in administering the trial,

- improved efficacy in preparing for on-site monitoring,

- concentration to one site of skills about the substance and the disease.

On the other hand, one should be aware of the constraints:

- distance from the real situation in the centre,

- feedback of information is dependent on the investigators' understanding of the protocol and requires considerable and repeated training and information activities for investigators,

- shift of workload onto the investigator, and

- limitations associated with the feedback of confidential information (e.g. copies of laboratory reports which must be made anonymous).
Finally this method is facilitated by the use of electronic case report forms which do, however, impose other limitations in order to guarantee the origin of the data (electronic signature) and their integrity (secure audit trail).

\subsubsection{Method 3: Monitoring by Sampling}

Three levels of sampling are possible:

- data sampling,

- case sampling, and

- centre sampling.

When this technique is used it must always be accompanied by a predefined strategy of activities to be applied depending on the result observed, i.e. the quality of sampling must not only be confirmed but above all an approach must be defined based on the quality observed. Predefined rules may therefore be applied, adapted on an individual case basis either upwards (for all centres) if the quality of the sample is inadequate or downwards (for the centre in question) if the quality of the sample is considered to be satisfactory.

However, it must be stressed that in a clinical trial the different measurement variables have different impact on the results of the trial, and the errors identified therefore have unequal consequences in terms of severity: the number of acceptable errors must therefore take account of this severity. In addition, some errors associated with rare events are difficult to detect.

\section{Adaptation of measures relating to the investigational medicinal product}

The discussion about the investigational medicinal product was organised around the circuit of the medicinal product(s) and its (their) traceability (labelling, dispensing, compliance).

This proceeded through concrete examples, and for each example the challenges were analysed in terms of risk, impact on the quality of results and impact on medical practices opening into proposals to reduce the measures in some cases.

Prior to this work, the group considered that it was firstly necessary to clearly define whether the research was a trial on the medicinal product, and if so, to clearly define the medicinal product in question. The definition of "investigational medicinal product" in Directive 2001/20/EC ${ }^{[3]}$ is as follows: "a pharmaceutical form of an active substance or placebo being tested or used as a reference in a clinical trial, including products already with a marketing authorisation but used or assembled (formulated or packaged) in a way different from the authorised form, or when 
Table II. Classification of research by level of risk-DRC AP-HP.

\begin{tabular}{|c|c|c|c|c|c|}
\hline $\begin{array}{l}\text { Level } \\
\text { of Risk }\end{array}$ & $\begin{array}{l}\text { Clinical Trial } \\
\text { Gene or Cell Therapy }\end{array}$ & $\begin{array}{l}\text { Genetic } \\
\text { Pathophysiology }\end{array}$ & $\begin{array}{l}\text { Quality of Life } \\
\text { Questionnaires } \\
\text { Psychiatry }\end{array}$ & $\begin{array}{l}\text { Imaging } \\
\text { Radiology } \\
\text { Radiotherapy } \\
\text { Isotopes Surgery }\end{array}$ & Medical devices \\
\hline Risk B & $\begin{array}{l}\text { Phase IV } \\
\text { Phase III } \\
\text { on association of } \\
\text { substances with MA }\end{array}$ & $\begin{array}{l}\text { Invasive depending on } \\
\text { type of procedure, with } \\
\text { injection depending on } \\
\text { substance }\end{array}$ & $\begin{array}{l}\text { If probing } \\
\text { questionnaire in } \\
\text { serious disease }\end{array}$ & $\begin{array}{l}\text { Standard but poorly } \\
\text { known technique. } \\
\text { Routine surgery }\end{array}$ & $\begin{array}{l}\text { CE marked MD, class IIa, Ilb } \\
\text { or III used routinely CE MD, } \\
\text { class Ila outside of } \\
\text { indication. Non-CE MD, class I } \\
\text { (except for invasive or active) }\end{array}$ \\
\hline Risk C & $\begin{array}{l}\text { Phase III } \\
\text { New indication } \\
\text { At risk population }\end{array}$ & $\begin{array}{l}\text { Invasive depending on } \\
\text { type of procedure, with } \\
\text { injection depending on } \\
\text { substance }\end{array}$ & - & $\begin{array}{l}\text { Learning phase Gen- } \\
\text { eralisation of a new } \\
\text { technique }\end{array}$ & $\begin{array}{l}\text { CE marked MD class IIb } \\
\text { outside of indication } \\
\text { CE marked MD class III with } \\
\text { limited experience }\end{array}$ \\
\hline
\end{tabular}

CE: European Community; MD: medical devices.

Table III. Level of monitoring depending on risk-DRC AP-HP.

\begin{tabular}{|c|c|c|c|c|}
\hline Level of Risk & Risk $A$ & Risk B & Risk C & Risk D \\
\hline $\begin{array}{l}\text { Preliminary meeting Classification } \\
\text { Scientific undertaking/ GCP }\end{array}$ & - & - & - & - \\
\hline Consent of people included & Not in real time & - & - & - \\
\hline SAE/Safety / New findings & - & - & - & - \\
\hline $\begin{array}{l}\text { Baseline Monitoring } \\
\text { (6 points) }\end{array}$ & - & - & - & - \\
\hline $\begin{array}{l}\text { Percentage of dossiers monitored } \\
100 \%\end{array}$ & - & $1^{\text {st }} /$ centre $1^{\text {st }} /$ investigator & 10 to $20 \%$ & $100 \%$ \\
\hline
\end{tabular}

used for an unauthorised indication, or when used to gain further information about the authorised form".

This definition is currently being debated at the community level and is being clarified in terms of circuit and traceability requirements, depending on the different possible trial scenarios.

The issue, particularly in comparative trials, of standard treatments for management of the pathology (background therapy) is crucial: the group's recommendation is to try as much as possible to remove the standard treatment(s) from the definition of the investigational medicinal product if the aim of the trial raises no specific direct question on the background therapy and if, of course, the use of this standard treatment is validated by the MA.

The GCP texts ${ }^{[6]}$ and Good Manufacturing Practices ${ }^{[10]}$ require investigational medicinal products to be labelled specifically and their circuit and traceability to be documented.
The organisation of the traceability method must, above all, answer the following questions: does the possible absence of specific labelling:

- have an impact on patient safety?

- have an impact on the robustness of the trial results?

- have an impact on the measurement of compliance?

By reviewing different examples, the group constructed a simple "baseline" decision-making tree which takes three factors into account:

- factor 1: Is the medicinal product investigational? Is it included in the definition of the IMP in the context of the trial?

- factor 2: Do the design and objectives of the trial require specific packaging for the research? 
- factor 3: Is the risk of use or incorrect use greater than that of usual practice?

If at least factors 1 and 2 are present or if at least factors 1 and 3 are present, specific labelling is required and essential for the research.

In the other situations, changes in the specific packaging and labelling for the trial may be considered on an individual case basis, depending on the limitations associated with the trial.

So some situations make labelling difficult - but not always impossible - and must also be taken into account in the decisionmaking tree.

For example:

- when the investigational medicinal products are not clearly defined and set by the research but for example only identified by their ATC class, or

- when the circuit of the medicinal product is on an ambulatory basis via primary care dispensing pharmacies.

Finally, in other situations, labelling may even be considered to be of limited utility:

- when the medicinal product is contained in a preparation produced in a hospital pharmacy (PUI): only the preparation destined for the trial is labelled,

- when a batch of identifiable medicinal product may be reserved for the clinical trial, or

- when a medicinal product is administered under the direct control of the investigator (Intra Venous administration) and documentation is generated in real time.

Regardless of the solution adopted, it is in all cases essential and absolutely necessary, and particularly so if a simplification is adopted, that detailed appropriate documentation be drawn up in advance and during the trial, together with a tracability follow up.

\section{Adaptation of administrative procedures for administration/declaration of adverse events}

The vigilance requirements for clinical trials have been clearly defined in Directive 2001/20/EC ${ }^{[3]}$ and in its transposition in France through the Public Health Law, number 2004-806 dated 9 August 2004. ${ }^{[4]}$

The collection and circulation of information on adverse effects are particularly important because of the often serious decisions which may flow from these on the use of the trial medicinal product. ${ }^{[1]}$

The discussion on possible simplification of monitoring vigilance in a biomedical research project was based firstly on the type of procedures which could be simplified (Sustained Unexpected Adverse Event ("SUSAR"), coding, non-serious AE, declarations, annual safety report, etc.).

It emerged that adapting the application of GCP in this field was extremely limited and that this could possibly, and only, be considered for research on a medicinal product which already has MA and which has a safety profile that is already well known: in this situation and only in this situation, of all the vigilance requirements only one simplification can be considered, concerning the recording of non-serious adverse events by the investigator: this recording may be made via the production and use of a standardised recording list.

In terms of vigilance for clinical trials, it emerged that the most useful activities to consider were assistance for investigators and sponsors. This assistance should be based in particular on causality assessments, using a systematic approach, taking account of the time course from taking the medicinal product and the clinical symptoms and signs of the event. Similarly, aid/training for investigators to evaluate the severity of an adverse event may be provided. A severity scoring scale? for adverse events has been developed for this purpose within ANRS. ${ }^{[1]}$

European Directive 2001/20/EC dated 4 April 2001, and its transposition in France in the Public Health Law of 9 August 2004, considerably increases the responsibility of the sponsor in terms of vigilance. In the face of this, it appears necessary for institutional research to pool the resources and tools needed to meet the new requirements. Circular DHOS/OPRC/2005/252 of 26 May 2005 relates to the new governance of the University Hospitals and defines the need to professionalize clinical research and recognise the research staff by establishing clinical research departments or federations within establishments. It also stipulates, through a call for projects, the creation of inter-regional clinical research structures responsible for performing specific leadership and support activities which cannot be performed effectively at the local level, in particular the execution of certain specific sponsor activities such as the quality assurance system, vigilance, etc.

This pooling of vigilance could in particular relate to:

- human resource: the "vigilance" staff,

- computer tools: database,

- the MedDRA reference text for coding (licence, training), and - training on the Eudravigilance CT module.

In conclusion, it is possible to adapt the application of GCP and this is envisaged within the texts. Such an adaptation must take account firstly of the features of the research: what are the objectives/risks/challenges, rather than the type of sponsor (academic or industrial). The choices for adaptation must be predetermined, documented and justified: if necessary they should also be assessed during the trial. Finally, there is little scope for reducing vigilance. 


\section{Participants}

Abiteboul M. (Quintiles), Augiers de Cremiers F. (Wyeth Lederle), Bélorgey C. (Afssaps), Blazejewki S. (Université Victor Segalen, Bordeaux), Bouxin-Métro A. (ANRS), Chene G. (INSERM, Bordeaux), Couderc M. (Sanofi Synthélabo), DananDurieux M. (Sanofi Aventis), Deneulin A. (Astra Zeneca), Faurisson F. (Eurordis), Libersa C. (CHRU, Lille), Malchiodi M. (Roche), Marquet P. (Hôpital Dupuytren, Limoges), Orefice C. (3M Santé), Postaire E. (DRCT, INSERM, Paris), Rancinan C. (INSERM, Bordeaux), Reynier J.-C. (AP-HM, Marseille), Spriet A. (Spriet Conseil, Paris), Tibi A. (AGEPS, Paris), Toneatti C. (Institut Pasteur, Paris), Treluyer J.-M. (Hôpital Saint Vincent de Paul, Paris), Vicaut A. (Hôpital Fernand Widal, Paris), VincentPelletier A. (CPCET, Marseille).

\section{References}

1. Bonnes pratiques des Essais Cliniques des médicaments- Alain Spriet (Paris), Thérèse Dupin-Spriet (Lille). Troisième édition. ISBN 3-8055-7723-0. Editions Karger, Paris

2. Note for guidance on Good Clinical practice : ICH harmonised tripartite guidelines, CHMP/ICH/135/95. http://www . ich.org

3. Directive 2001/20/CE du parlement européen et du conseil du 4 avril 2001 concernant le rapprochement des dispositions législatives, règlementaires et administratives des Etats membres relatives à l'application des bonnes pratiques cliniques dans la conduite d'essais cliniques de médicaments à usage humain. Journal Officiel des Communautés Européennes /1.5.2001 /L121/34 http://pharmacos. eudra.org
4. Loi $n^{\circ}$ 2004-806 du 9 août 2004 relative à la politique de santé publique http: //www. legifrance.gouv

5. Décret $n^{\circ}$ 2006-477 du 26 avril 2006 modifiant le chapitre Ier du titre II du livre Ier de la première partie du code de la Santé Publique relatifs aux recherches biomédiacles (dispositions réglementaires) J. O. n 99 du 27 avril 2006 page 6332 texte $\mathrm{n}^{\circ} 10$ http: //www . legifrance.gouv

6. Directive 2005/28/CE de la Commission du 8 avril 2005 fixant des principes et des lignes directrices détaillées relatifs à l'application de bonnes pratiques cliniques en ce qui concerne les médicaments expérimentaux à usage humain, ainsi que les exigences pour l'octroi de l'autorisation de fabriquer ou d'importer ces médicaments. Journal Officiel des Communautés Européennes 9.4.2005/L 91/13

7. ICH Harmonised Tripartite Guideline. Pharmacovigilance planning E2E recommanded for adoption at step 4 of the ICH Process on 18 November 2004 by the ICH Steering Committee http://www.ich.org

8. Essais cliniques, théorie, pratique et critique- G. Bouvenot, M. Vray Editions Flammarion Medecine-Sciences, Paris

9. Medical Research Council, UK, Notes on Good practice for Research Organisations in the Management of a Portfolio of Trials 3: management of risk

10. Directive 2003/94/CE de la Commission du 8 octobre 2003 établissant les principes et lignes directrices de bonnes pratiques de fabrication concernant les médicaments à usage humain et les médicaments expérimentaux à usage humain. Journal Officiel des Communautés Européennes /14.10.2003 /262/22 http: //pharmacos. eudra.org

11. Grille de cotation de gravité des évènements indésirables, disponible sur le site de l'ANRS http://www/anrs. fr

Correspondence and offprints: Soizic Courcier, Bristol Myers Squibb, 3 rue Joseph Monnier, 92578 Rueil Malmaison, France.

E-mail: soizic.courcier@bms.com 